\title{
$\mathrm{Bi}$ 를 첨가한 백색 $\mathrm{LED}$ 용 $\mathrm{ZnS}: \mathrm{Mn}$ 황색형광체의 발광특성
}

\author{
정종훈 $\cdot$ 유 일 ${ }^{\dagger}$ \\ 동의대학교 물리학과, 부산 IT융합부품연구소
}

\section{Luminescent Characteristics of Bi Co-doped ZnS:Mn Yellow Phosphors for White Light Emitting Diodes}

\author{
Jong-Hun Jung and $\mathrm{Il} \mathrm{Yu}^{\dagger}$ \\ Department of Physics, Dong-Eui University and Convergence of IT Devices Institute Busan, \\ Busan 614-714, Korea
}

(2010년 10월 20일 접수 : 2010년 12월 7일 최종수정 : 2010년 12월 7일 채택)

\begin{abstract}
Bi co-doped $\mathrm{ZnS}: \mathrm{Mn}$,Bi yellow phosphors for white light emitting diodes were prepared by the conventional solidstate reaction method. The optical and structural properties of $\mathrm{ZnS}: \mathrm{Mn}, \mathrm{Bi}$ phosphors were investigated by x-ray diffraction, scanning electro microscopy and photoluminescence. ZnS:Mn,Bi phosphors showed XRD patterns of hexagonal structure. The photoluminescence of $\mathrm{ZnS}: \mathrm{Mn}, \mathrm{Bi}$ phosphors showed spectra extending from 480 to $700 \mathrm{~nm}$, peaking at $580 \mathrm{~nm}$. The photoluminescence of $580 \mathrm{~nm}$ in the $\mathrm{ZnS}: \mathrm{Mn}, \mathrm{Bi}$ phosphors was associated with the 4T1 $\rightarrow 6 \mathrm{~A} 1$ transition of the Mn2+ ions. The highest photoluminescent intensity of the phosphors under $405 \mathrm{~nm}$ and $450 \mathrm{~nm}$ excitation was obtained at Bi concentration of $7 \mathrm{~mol} \%$. The optimum mixing conditions with epoxy and yellow phosphor for white light emitting diodes were observed in a ratio of epoxy:yellow phosphor of 1:3.5. The CIE chromaticity of the white LED at the 1:3.5 ratio was $\mathrm{X}=0.3454$ and $\mathrm{Y}=0.2449$.
\end{abstract}

Key words ZnS, Luminescence, Mn, Bi, LED.

\section{1. 서 론}

LED (Light Emitting Diode)는 P-N 접합 부근이나 활성 층에서 전자와 홀의 결합에 의해 빛을 방출하는 소자로 $\mathrm{LCD}$ 용 백라이트, 자동차 헤드램프, 일반조명 등으로 그 용 도가 점차 확대되고 있다. $\mathrm{LED}$ 는 반도체 소자로 이루어 져 있기 때문에 백열등 등의 다른 발광소자에 비해 신뢰 성이 높고, 전력소비는 기존 전구의 $1 / 12$ 에 불과하고, 수 명은 전구의 100 배 이상인 반면, 반응속도는 기존 전구보 다 1000 배 이상 빠른 특징이 있다. 또한 LED는 백열전 구 등과 달리 단색에 가깝고, 어떤 반도체 재료를 선택하 느냐에 따라 적색, 오렌지, 녹색, 청색 등 다양한 파장의 칼라 구현이 가능하다. ${ }^{1)}$

백색 $\mathrm{LED}$ 를 구현 하는 방법에는 크게 두 가지로 청색 $\mathrm{LED}$ 칩 위에 황색 형광체 $\mathrm{YAG}: \mathrm{Ce}\left(\mathrm{Y}_{3} \mathrm{AlO}_{12}: \mathrm{Ce}^{3+}\right)$ 를 도포 하여 백색 $\mathrm{LED}$ 를 구현하는 방법과 근자외선 LED 칩에 적색, 녹색, 청색의 형광체를 조합하여 구현하는 방법으로 나눌 수 있다. ${ }^{2)}$ 청색 $\mathrm{LED}$ 와 황색 형광체를 이용하는 방 법은 청색과 황색의 파장 간격이 넓기 때문에 CT (Color

Corresponding author

E-Mail : 0324yu@deu.ac.kr
Temperature)와 CRI (Color Rendering Index)의 조절이 어렵다는 단점이 있다. 근자외선 $\mathrm{LED}$ 칩을 이용한 백색 $\mathrm{LED}$ 는 아주 넓은 파장대의 스펙트럼을 가지고 있어 색 안정성의 확보와 $\mathrm{CT}, \mathrm{CRI}$ 의 조절이 가능하나 발광 효율 이 낮은 단점이 있어 발광 효율을 더욱 개선할 필요가 있 다. ${ }^{3)}$ 기존 보고에 의하면 발광효율의 개선을 위해 $\mathrm{ZnS:Mn}$ 형광체에 활성이온(activator)으로 $\mathrm{Cu}, \mathrm{Cl}, \mathrm{Ag}$ 등을 첨가한 연구가 많이 진행되어 왔다. 하지만 기존의 $\mathrm{ZnS}$ 형광체 는 $254 \mathrm{~nm}$ 나 $365 \mathrm{~nm}$ 를 여기원으로 발광특성을 연구하였 다. 백색 LED에 적합한 형광체를 연구하기 위해서는 LED 칩에서 나오는 405 나 $450 \mathrm{~nm}$ 의 빛을 여기원으로 발광할 수 있는 형광체를 연구 하는 것이 필요하다.

따라서 본 연구에서는 $405 \mathrm{~nm}$ 와 $450 \mathrm{~nm}$ 여기에 적합한 형광체를 얻기 위해 $\mathrm{ZnS}: \mathrm{Mn}, \mathrm{Bi}$ 형광체를 공기중에서 고 상반응법으로 만들어 $\mathrm{Bi}$ 의 농도 변화에 따른 결정성과 입 자의 형태를 조사하였고, $405 \mathrm{~nm}$ 와 $450 \mathrm{~nm}$ 여기조건에 따 른 발광 특성을 연구하였다.

\section{2. 실험 방법}

$\mathrm{ZnS}: \mathrm{Mn}$ 형광체의 모체와 활성제로 $\mathrm{ZnS}$ (Aldrich, 99.9\%), 
$\mathrm{MnSO}_{4} \cdot 5 \mathrm{H}_{2} \mathrm{O}$ (Chemicals, 99.99\%), Sulfur (Kanto chemical, $99.9 \%), \mathrm{Bi}\left(\mathrm{NO}_{3}\right)_{3} \cdot 5 \mathrm{H}_{2} \mathrm{O}$ (Aldrich $\left.99.999 \%\right)$ 융제로 $\mathrm{NH}_{4} \mathrm{Cl}$ (Tedia, 99.99\%)을 출발 원료로 사용하였다. $\mathrm{Mn}$ 의 농도 는 $0.5 \mathrm{~mol} \%$, 융제로 사용되는 $\mathrm{NH}_{4} \mathrm{Cl}$ 의 농도는 $15 \mathrm{~mol} \%$ 로 고정 하고, $\mathrm{Bi}$ 의 농도를 $0 \sim 10 \mathrm{~mol} \%$ 로 변화시켰다. 볼 밀과정을 통해 균일하게 혼합된 분말은 $1000^{\circ} \mathrm{C}$ 에서 4 시 간 동안 공기중에서 일반적인 고상반응법으로 형광체를 합 성하였다. 백색 $\mathrm{LED}$ 는 청색 $\mathrm{LED}$ 칩 위에 에폭시와 $\mathrm{ZnS}$ : $\mathrm{Mn}, \mathrm{Bi}$ 형광체를 $1: 0$ 비율에서 1:4 비율까지 변화시켜 도 포한 후, $150^{\circ} \mathrm{C}$ 에서 2 시간 동안 경화시켰다. 합성된 형 광체의 결정구조 및 형태는 X선 회절기(X-ray diffraction, XRD RIGAKU 社) 와 주사전자현미경(SEM)을 사용하여 확인하였다. Photoluminescence (PL)은 여기광원으로 Xe 램프 $405 \mathrm{~nm}$ 와 $450 \mathrm{~nm}$ 를 사용해 발광특성을 조사 하였 다. 발광스펙트럼과 LED특성은 DARSA PRO-5000을 이 용하여 $400 \mathrm{~nm} 700 \mathrm{~nm}$ 의 범위에서 분석하였고, LED 특 성은 $2.7 \mathrm{~V}$ 의 전압을 인가하여 발광특성을 측정하였다.

\section{3. 결과 및 고찰}

Fig. 1는 $\mathrm{Zn}: \mathrm{Mn}$ 형광체의 $\mathrm{Bi}$ 농도변화에 따른 $\mathrm{ZnS}: \mathrm{Mn}, \mathrm{Bi}$ 형광체의 XRD 패턴 결과이다. 그림에서와 같이 JCPDS의 비교에서 $\mathrm{ZnS}: \mathrm{Mn}, \mathrm{Bi}$ 는 $\mathrm{Bi}$ 농도에 관계없이 (100), (101)면 의 hexagonal 구조가 형성되어 있음을 확인할 수 있었다. $\mathrm{Bi}$ 농도가 증가함에 따라 $7 \mathrm{~mol} \%$ 이상에서 $\mathrm{Bi}_{2} \mathrm{O}_{3}$ 의 (122) 와 (210) 면이 나타났고, $\mathrm{ZnS}$ 의 hexagonal의 주피크(100) 면은 $\mathrm{Bi}_{2} \mathrm{O}_{3}$ 피크와 중첩되어 $\mathrm{XRD}$ 세기가 증가하는 것을 확인 할 수 있었다.

Fig. 2는 $\mathrm{ZnS}: \mathrm{Mn}$ 형광체의 $\mathrm{Bi}$ 농도 변화에 따른 $\mathrm{SEM}$ 사진을 나타낸 것이다. 그림에서와 같이 $\mathrm{Bi}$ 를 첨가하지 않

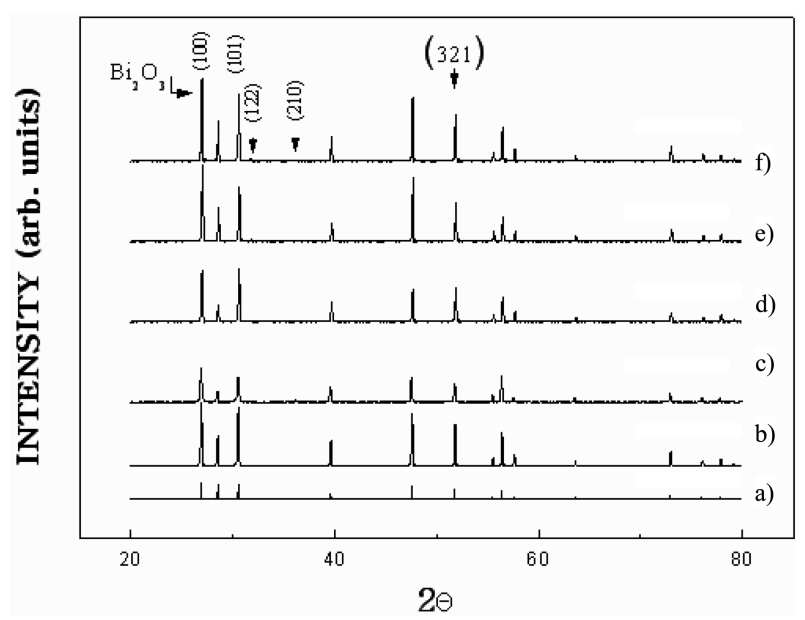

Fig. 1. XRD patterns of $\mathrm{ZnS}: \mathrm{Mn}$ phosphors for various $\mathrm{Bi}$ concentration; a) $\mathrm{ZnS}$, b) Bi $0 \mathrm{~mol} \%$, c) Bi $3 \mathrm{~mol} \%$, d) Bi $5 \mathrm{~mol} \%$, e) Bi $7 \mathrm{~mol} \%$ and f) $\mathrm{Bi} 10 \mathrm{~mol} \%$.
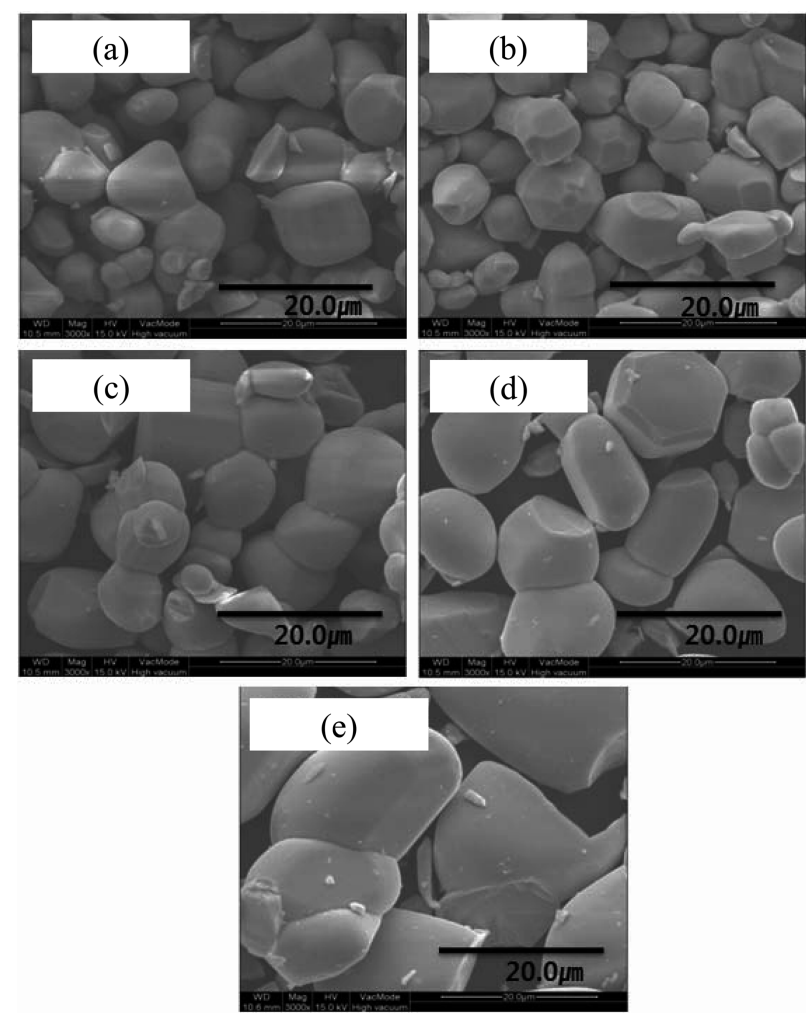

Fig. 2. SEM of ZnS:Mn phosphors for various Bi concentration. a) Bi $0 \mathrm{~mol} \%$, b) Bi $3 \mathrm{~mol} \%$, c) Bi $5 \mathrm{~mol} \%$, d) Bi $7 \mathrm{~mol} \%$ and e) $\mathrm{Bi}$ $10 \mathrm{~mol} \%$.

은 $\mathrm{ZnS}: \mathrm{Mn}$ 형광체의 입자 크기는 약 $8 \mu \mathrm{m}$ 이고, $\mathrm{Bi}$ 를 7 $\mathrm{mol} \%$ 첨가한 입자의 크기는 약 $13 \mu \mathrm{m}$ 그리고 $10 \mathrm{~mol} \%$ 첨가한 경우는 약 $23 \mu \mathrm{m}$ 로 증가하였다. 그리고 $\mathrm{Bi}$ 농도 가 $7 \mathrm{~mol} \%$ 까지는 입자표면이 깨끗한 것을 확인 할 수 있었지만, $\mathrm{Bi}$ 농도가 $10 \mathrm{~mol} \%$ 인 경우 미 반응한 $\mathrm{Bi}_{2} \mathrm{O}_{3}$ 가 입자표면에 붙어 매끄럽지 못한 형상을 하고 있는 것을 관찰할 수 있었다. 이는 발광효율의 저하를 야기 시킬 수 있을 것으로 보여진다.

Fig. 3은 Xe-Lamp의 $405 \mathrm{~nm}$ 를 여기파장으로 하여 측 정한 $\mathrm{Bi}$ 농도 변화에 따른 $\mathrm{ZnS}: \mathrm{Mn}$ 형광체의 $\mathrm{PL}$ 스펙트 럼이다. $\mathrm{ZnS}: \mathrm{Mn}, \mathrm{Bi}$ 형광체의 $580 \mathrm{~nm}$ 부근에서 황색발광 은 $\mathrm{Mn}^{2+}$ 의 ${ }^{4} \mathrm{~T}_{1}$ 에서 ${ }^{6} \mathrm{~A}_{1}$ 으로 전이에 의한 피크이다. ${ }^{4}$

기존의 연구결과에서 $\mathrm{CaS} ; \mathrm{Bi}$ 는 $\mathrm{Bi}$ 농도가 증가함에 따 라 $500 \mathrm{~nm}$ 부근의 $\mathrm{PL}$ 세기가 증가하는 것으로 보고되어 있다. ${ }^{5)}$ 본 연구에서도 그림에서와 같이 $\mathrm{Bi}$ 농도를 $7 \mathrm{~mol} \%$ 첨가한 $\mathrm{ZnS}: \mathrm{Mn}: \mathrm{Bi}$ 형광체에서 $500 \mathrm{~nm}$ 부근의 언저리는 $\mathrm{Bi}$ 로 판단되어지는 피크가 나타났고, 이는 $\mathrm{Bi}$ 농도가 증가 하면서 $500 \mathrm{~nm}$ 부근 피크의 세기는 감소하고 $580 \mathrm{~nm}$ 부 근의 피크는 증가하였다. 이 같은 $\mathrm{PL}$ 세기의 증가는 $\mathrm{Bi}^{3+}$ 에서 $\mathrm{Mn}^{2+}$ 로 에너지 전이에 의해 $\left.{ }^{4} \mathrm{~T}_{1}{ }^{4} \mathrm{G}\right)$ 전이에 의한 황색 발광이 강해지게 된 것이라 생각된다.)

즉, $\mathrm{Bi}^{3+}$ 이온은 ${ }^{5} \mathrm{D}_{0}$ 에서 ${ }^{7} \mathrm{~F}_{1}$ 준위로 전자 전이에 의한 
$581 \mathrm{~nm} 593 \mathrm{~nm}$ 영역에서 발광하며 $\mathrm{Bi}$ 농도가 증가하면서 $580 \mathrm{~nm}$ 부근의 $\mathrm{Bi}^{3+}$ 이온에서 $\mathrm{Mn}^{2+}$ 이온으로 에너지 전 이가 발생하여 발광세기가 증가한 것으로 판단된다. 그리 고 발광세기는 $\mathrm{Bi}^{3+}$ 농도가 $7 \mathrm{~mol} \%$ 일때 가장 우수했으나 $7 \mathrm{~mol} \%$ 이상에서는 발광 세기가 감소하는 것을 관찰 할 수 있었다. 이 같은 결과는 앞의 XRD에서 나타난 미 반 응 $\mathrm{Bi}_{2} \mathrm{O}_{3}$ 이 형광체 모체 내에서 killer로서 작용하고 또한 $\mathrm{SEM}$ 결과에서 $\mathrm{Bi} 10 \mathrm{~mol} \%$ 첨가한 입자의 결정면이 고 르지 못한 것이 원인인 것으로 생각되어진다. ${ }^{7)}$

Fig. 4는 $450 \mathrm{~nm}$ 여기 시 $\mathrm{Bi}$ 농도에 따른 $\mathrm{ZnS}: \mathrm{Mn}, \mathrm{Bi}$ 형 광체의 $\mathrm{PL}$ 스펙트럼의 변화를 나타낸 것이다. $\mathrm{ZnS}: \mathrm{Mn}, \mathrm{Bi}$ 의 발광 파장은 $580 \mathrm{~nm}$ 였고, $450 \mathrm{~nm}$ 로 여기한 시료와 마찬가지로 $\mathrm{Bi} 7 \mathrm{~mol} \%$ 첨가 후 파장은 $580 \mathrm{~nm}$ 부근의 황 색 발광을 하는 것을 확인 할 수 있었다. $\mathrm{ZnS}: \mathrm{Mn}, \mathrm{Bi}$ 형 광체에 $\mathrm{Bi}$ 를 첨가함으로써 점차적으로 발광 특성이 향상

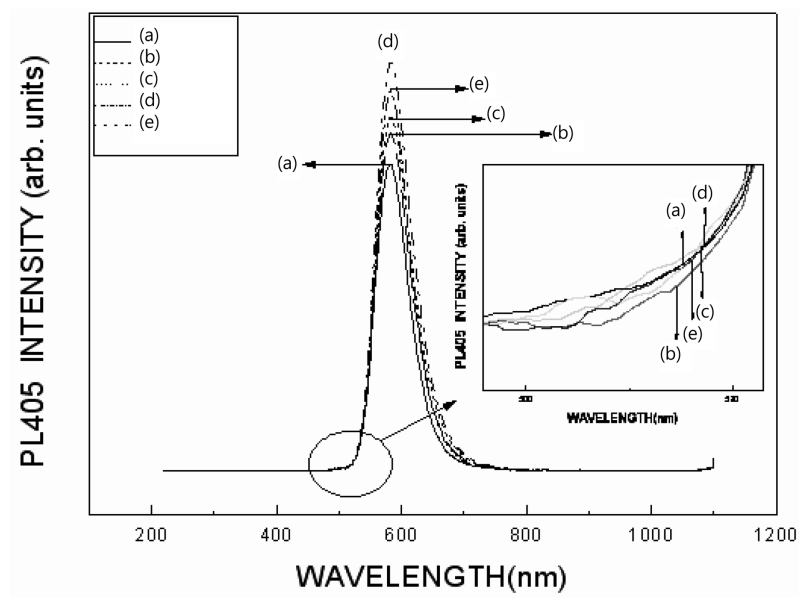

Fig. 3. PL spectra of $\mathrm{ZnS}: \mathrm{Mn}$ phosphors for various $\mathrm{Bi}$ concentration under the $405 \mathrm{~nm}$ excitation. a) Bi $0 \mathrm{~mol} \%$, b) Bi $3 \mathrm{~mol} \%$, c) Bi $5 \mathrm{~mol} \%$, d) Bi $7 \mathrm{~mol} \%$ and e) Bi $10 \mathrm{~mol} \%$.

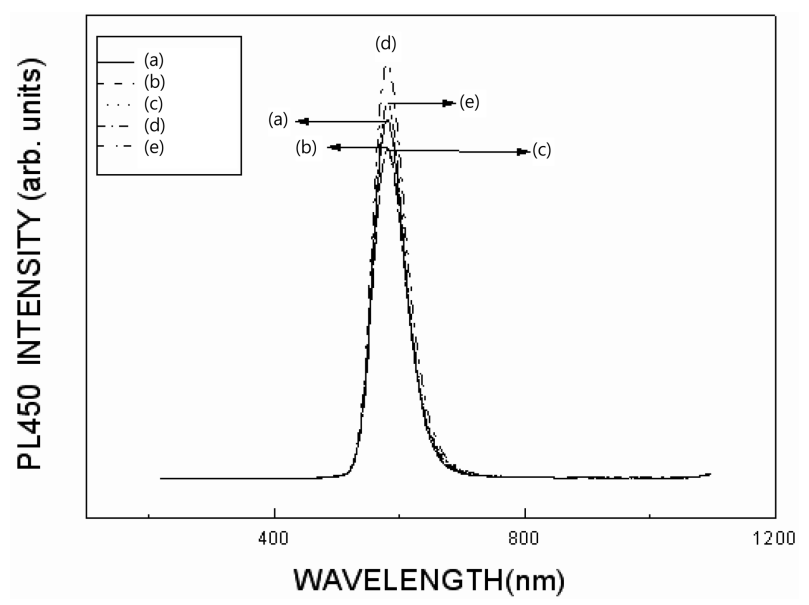

Fig. 4. PL spectra of $\mathrm{ZnS}: \mathrm{Mn}$ phosphors for various $\mathrm{Bi}$ concentration under the $450 \mathrm{~nm}$ excitation. a) Bi $0 \mathrm{~mol} \%$, b) Bi $3 \mathrm{~mol} \%$, c) Bi $5 \mathrm{~mol} \%$, d) Bi $7 \mathrm{~mol} \%$ and e) Bi $10 \mathrm{~mol} \%$.
되는 것을 관찰 할 수 있었다. $405 \mathrm{~nm}$ 여기 결과와 동일 하게 $\mathrm{Bi} 7 \mathrm{~mol} \%$ 첨가한 형광체의 $\mathrm{PL}$ 세기가 가장 좋게 나 타났다.

Fig. 5는 $\mathrm{ZnS}: \mathrm{Mn}$ 형광체의 $\mathrm{Bi}$ 농도 변화에 따른 $405 \mathrm{~nm}$ 와 $450 \mathrm{~nm}$ 로 여기 시킨 $\mathrm{ZnS}: \mathrm{Mn}, \mathrm{Bi}$ 형광체의 색좌표 변 화를 $\mathrm{CIE}$ 좌표계로 나타낸 것이다. $405 \mathrm{~nm}$ 로 여기한 $\mathrm{ZnS}$ : $\mathrm{Mn}$ 형광체에 $\mathrm{Bi}$ 를 첨가하지 않았을 경우, 색좌표는 $\mathrm{X}=$ $0.5258, \mathrm{Y}=0.4709$ 로 $\mathrm{Bi}$ 의 농도가 $7 \mathrm{~mol} \%$ 인 경우, $\mathrm{X}=$ $0.5346, \mathrm{Y}=0.4629$ 로 나타났다. $450 \mathrm{~nm}$ 로 여기한 $\mathrm{ZnS}: \mathrm{Mn}$ 형광체에 $\mathrm{Bi}$ 를 첨가 하지 않았을 경우의 색좌표는 $\mathrm{X}=$ $0.5258, \mathrm{Y}=0.4709$ 으로 나타났으며, $\mathrm{Bi}$ 의 농도가 $7 \mathrm{~mol} \%$ 인 경우 $\mathrm{X}=0.5346, \mathrm{Y}=0.4629$ 로 나타났다. 그림에서와 같이 $\mathrm{ZnS}: \mathrm{Mn}$ 형광체에 $\mathrm{Bi}$ 를 첨가함에 따라 색좌표의 $\mathrm{X}$ 는 증가하고, $\mathrm{Y}$ 는 감소하는 것을 확인 할 수 있었다.

Fig. 6 은 $450 \mathrm{~nm}$ 파장의 빛을 발광하는 청색 LED칩 위

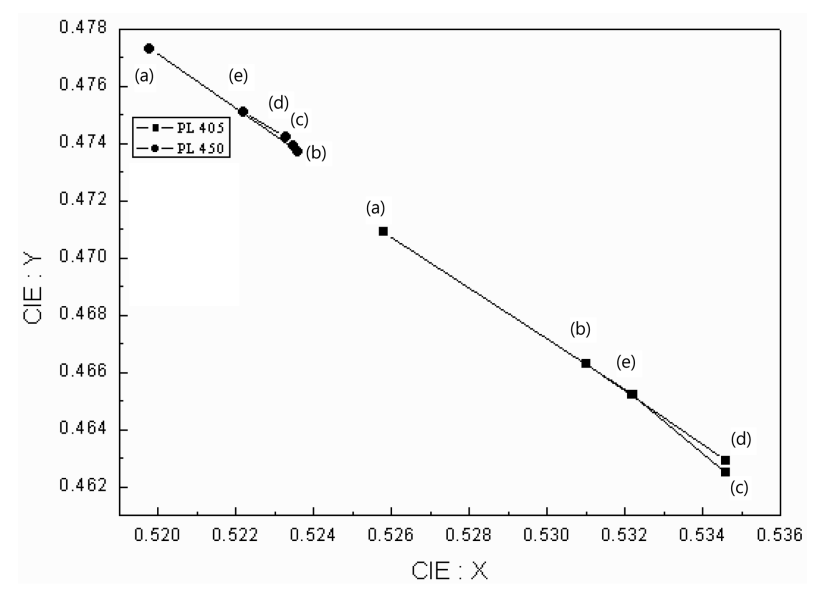

Fig. 5. CIE diagram of $\mathrm{ZnS}: \mathrm{Mn}$, Phosphors and $\mathrm{ZnS}: \mathrm{Mn}, \mathrm{Bi}$ Phosphors under the $405 \mathrm{~nm}$ excitation. a) Bi $0 \mathrm{~mol} \%$, b) Bi $3 \mathrm{~mol} \%$, c) $\mathrm{Bi} 5 \mathrm{~mol} \%$, d) $\mathrm{Bi} 7 \mathrm{~mol} \%$ and e) Bi $10 \mathrm{~mol} \%$.

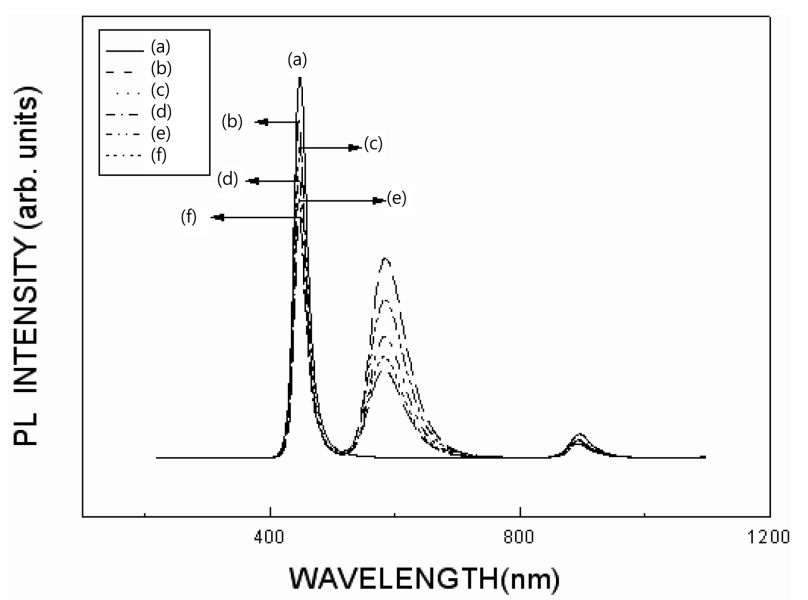

Fig. 6. PL spectra of ZnS:Mn phosphors for various Bi concentration under the $450 \mathrm{~nm}$ excitation. (a) 1:0, (b) 1:2, (c) 1:1.25, (d) 1:3, (e) $1: 3.5$ and (f) $1: 4$. 


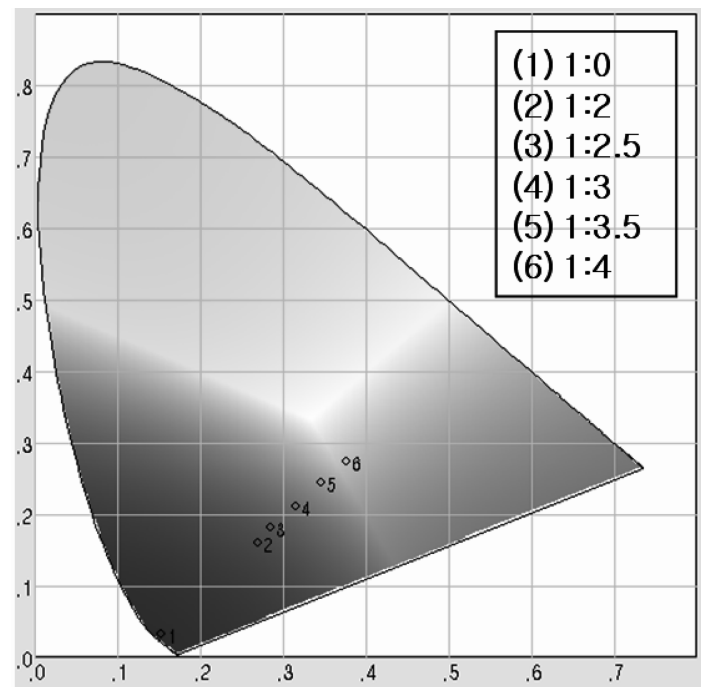

Fig. 7. CIE diagram of blue chip-based ZnS:Mn,Bi LED.

에 $\mathrm{PL}$ 에서 발광세기가 가장 우수한 $7 \mathrm{~mol} \% \mathrm{Bi}$ 를 첨가한 형광체와 에폭시의 비율을 변화시켜 백색 $\mathrm{LED}$ 의 발광 특 성을 조사하였다. 에폭시와 형광체의 비율은 1:0에서 $1: 4$ 까지 변화시켜 주사기를 이용하여 LED 칩 위에 도포 하 였다. 백색 $\mathrm{LED}$ 의 발광은 그림에서와 같이 형광체의 비 율이 증가할수록 $450 \mathrm{~nm}$ 의 세기는 감소하였고, $580 \mathrm{~nm}$ 의 세기는 점차 증가하는 것을 확인 할 수 있었다.

Fig. 7은 에폭시와 형광체의 혼합 비율 변화에 따른 $\mathrm{LED}$ 의 색좌표를 나타내었다. 형광체의 비율이 증가할수록 색좌표가 백색으로 이동하는 것을 확인 할 수 있었다. 백 색 $\mathrm{LED}$ 는 에폭시와 형광체의 비율이 $1: 3.5$ 일 때 가장 백색에 가까운 빛을 보였다. 이때 색좌표는 $\mathrm{X}=0.3454$ $\mathrm{Y}=0.2449$ 로 나타났다. 하지만 1:4의 비율에서의 발광색 은 황색빛에 가까운 백색이 관찰되었다. 이때 색좌표는 $\mathrm{X}=0.3764 \mathrm{Y}=0.2748$ 로 변화하였다.

\section{4. 결 론}

$\mathrm{ZnS}: \mathrm{Mn}, \mathrm{Bi}$ 형광체를 공기중에서 고상반응법으로 제조하 여 발광특성을 분석 하였다. XRD 결과, 형광체는 hexagonal 구조가 형성되는 것을 확인 할 수 있었다. PL 측 정 결과, $\mathrm{Xe}$ 램프의 $405,450 \mathrm{~nm}$ 여기 시 $580 \mathrm{~nm}$ 부근의 황색 발광은 $\mathrm{Bi}$ 의 농도를 $7 \mathrm{~mol} \%$ 첨가 시 발광 세기가 가 장 좋은 것으로 나타났다. $\mathrm{Bi}$ 첨가로 $405 \mathrm{~nm}$ 로 여기한 형
광체의 색좌표는 $\mathrm{X}=0.5258, \mathrm{Y}=0.4709$ 에서 $\mathrm{X}=0.5346$, $\mathrm{Y}=0.4629$ 로 나타났고, $450 \mathrm{~nm}$ 에서는 $\mathrm{X}=0.5258, \mathrm{Y}=$ 0.4709 에서 $\mathrm{X}=0.5346, \mathrm{Y}=0.4629$ 로 나타났다. 백색 LED 구현은 에폭시와 형광체의 비율이 $1: 3.5$ 일 때 가장 백색에 가까운 $\mathrm{LED}$ 를 제작할 수 있었다.

\section{감사의 글}

이 논문은 2010 학년도 동의대학교 교내 연구비에 의 해 연구되었음 (2010AA095).

\section{참 고 문 헌}

1. S. Nakamura and G. Fasol, The Blue Laser Diode: GaN Based Light Emitters and Lasers, p.343, Springer, Berlin (1997).

2. S. -S. Kweon, J. -Y. Park and Y. -D. Huh, Kor. J. Mater. Res., 16(3), 145 (2006) (in Korean).

3. J. W. Moon, Y. H. Song, W. J. Park and D. H. Yoon, J. Kor. Cryst. Growth \& Cryst. Tech., 19(1), 15 (2009) (in Korean).

4. J. S. Kim, T. W. Kim, H. L. Park and S. D. Han, J. Kor. Soc. Imag. Sci. Tech., 10(4), 8 (2004) (in Korean).

5. H. S. Hwang, S. C. Kim and H. S. Choi, Sae Mulli, 30(5), 516 (1990) (in Korean).

6. S. -D. Han, A. -K. Kwon, H. -S. Lee, C. -H. Han, J. -D. Kim and J. Gwak, J. Kor. Sensor. Soc., 15(5), 323 (2006) (in Korean).

7. W. J. Park, M. K. Jung, S. G. Yoon and D. H. Yoon, J. Kor. Cryst. Growth \& Cryst. Tech., 16(3), 112 (2006) (in Korean). 